Keywords: Demoralization; Disaster; Hurricane; Posttraumatic Stress Disorder; Honduras; Longitudinal.

\title{
Demoralization and the longitudinal course of PTSD following Hurricane Mitch
}

\author{
Robert Kohn, MD \\ The Warren Alpert Medical School of Brown \\ University, Department of Psychiatry and \\ Human Behavior, Providence
}

USA

\begin{abstract}
Background and Objectives: Numerous studies of disasters have used measures of non-specific distress as outcome measures. The utility of these measures as predictive of the long-term outcome of disasters has remained unclear, in particular the relationship with PTSD. This study examines whether demoralization is predictive and a useful concept to examine the long-term outcome of disaster related PTSD.

Methods: The 1998 Hurricane Mitch that impacted Honduras was examined two-months $(\mathrm{n}=800)$ and two-years following the disaster in a longitudinal community-based sample of 604 adults. Respondents were selected from a stratified sample in Tegucigalpa based on exposure and social economic status. PTSD diagnosed using the CIDI module at both periods of time. Demoralization was measured using the PERI-D at 2-months post-disaster.

Results: The PERI-D, increased demoralization, was significantly associated with PTSD at two-month and two-years. In addition, increased demoralization was associated with increased risk of PTSD chronicity. Decreased demoralization was associated with PTSD remission. New onset PTSD was associated increased demoralization; however, the finding was not appreciated after controlling for potential confounders.

Conclusions: Demoralization can be measured using a simple screening questionnaire that may be a useful in identifying individuals who may be at increased risk for PTSD in the short-term, as well as in the long-term following a disaster.
\end{abstract}

Received: 27 September 2012

Revised: 3 December 2012

Accepted: 19 December 2012 


\section{Introduction}

Demoralization has as its clinical hallmark the state of "subjective incompetence", a selfperceived incapacity to perform tasks and express feelings deemed appropriate in a stressful situation, resulting in pervasive uncertainty and doubts about the future ${ }^{1}$. Subjective incompetence occurs when a person is facing a stressor that disconfirms assumptions about self and others and about the continuity of the past and present with the future, such as a disaster ${ }^{2}$. While demoralization and depression may coexist, they are distinct clinical entities, with the former being characterized by anhedonia and the latter being characterized by helplessness ${ }^{3}$.

Demoralization has seldom been examined specifically in disaster studies. Interestingly, one of the earliest disaster studies Buffalo Creek described the survivors as having experienced demoralization from being forced to give up long-standing ties with familiar places and people ${ }^{4}$. Numerous cross-sectional studies on disasters have utilized measures of non-specific distress, in particular the General Health Questionnaire (GHQ) ${ }^{5}$ and Symptom Reporting Questionnaire (SRQ) ${ }^{6}$. Of these, only a small number of studies have incorporated the GHQ or SRQ with a structured diagnostic interview that obtained a diagnosis of posttraumatic stress disorder (PTSD) $)^{7-10}$. Most studies used the measure of non-specific distress as the primary outcome.

Longitudinal studies of disasters are relatively rare. Neria only identified five such studies in a review of the literature on posttraumatic stress disorder and disasters ${ }^{11}$. Since that review two other studies have been published ${ }^{12,13}$. Although not specifically examining the diagnosis of PTSD a third study using the Posttraumatic Stress Scale examined the course of stress following an oil rig disaster from 1980-2007 by incorporating the GHQ$20^{14}$. None of these studies have focused specifically on the role of demoralization. Although nonspecific psychological distress has frequently been equated with demoralization, only four instruments have specifically been developed to measure this construct: Psychiatric Epidemiology Research Interview Demoralization Scale (PERI-D) ${ }^{15}$, Brief Cope Scale $^{2}$, Kissane et al.'s Demoralization Scale ${ }^{16}$, and the MMPI-2 Restructured Clinical Scale of Demoralization ${ }^{17}$.

The objective of this study is to examine whether demoralization is predictive and a useful concept to examine the long-term outcome of disaster related PTSD. The PERI-D was incorporated into a two-year longitudinal study of Hurricane Mitch in Honduras.

\section{Methods}

\section{The Disaster}

Hurricane Mitch struck Central America as a category 4 hurricane on October 25, 1998. By October 26 and until it began to dissipate on October 29 the wind speeds were up to $285 \mathrm{~km} /$ hour (150 miles/hour) making it a category 5 storm. Honduras suffered the brunt of this natural disaster. An estimated $1,393,669$ Hondurans were displaced by the hurricane, 6,600 were confirmed killed, with an additional 8,052 have never been accounted for ${ }^{18}$. There were also 11,998 persons reportedly injured.

\section{Sample Selection}

The study was conducted in December 1998 and at the beginning of January 1999 in Tegucigalpa two-months following the hurricane. Eight hundred adults were interviewed, 
stratified by neighborhoods representing three socioeconomic classes (SES): half being from the lowest SES, one-fourth from middle and one-fourth from high SES neighborhoods of the city. Each of the three SES strata was selected from two types of neighborhoods: highly impacted (people died, homes destroyed, or massive property damage) and less affected districts (no deaths, minor damage to home and property). Individuals from the lowest SES stratum from the highly impacted group were further subdivided into two additional groups: those residing in the community and those residing in shelters.

Housing units were selected from predetermined neighborhoods by counting the number of homes in the area and dividing by the number of households needed. When a home was selected, whether intact or destroyed, the residents were located, and, if unavailable found by talking to neighbors or workmen. If the residents of the home could not be located the subsequent house was to be selected. In some streets where homes were destroyed or in poorer neighborhoods where it was extremely difficult to count homes, consecutive households were selected.

When someone associated with the household was found they were interviewed, and asked to describe what happened to the home and the residents. All adults aged 15 and older in the home were subsequently listed by descending age, first males then females. By entering the number of eligible individuals into a Kish grid, the person to be interviewed for the mental health survey was determined ${ }^{19}$. For individuals living in a shelter all families were selected in the given shelters with the person interviewed from a given family determined using the Kish method.

\section{Interview Schedule}

The identified adult respondent based on the Kish table was first asked socio-demographic items. Beyond the typical gender, age, education and occupation items, questions about how the disaster changed the individual's occupation were inquired into. Each respondent was asked about six traumatic events that they may have experienced during the disaster: the house was damaged, witnessed someone being injured, witnessed someone die, was injured, lost one's belonging, and lost a pet. These items were used to create an exposure index ${ }^{7}$.

Demoralization, non-specific psychological distress, among the adults was measured using the PERI-D ${ }^{15}$. The PERI-D was developed from 8 of the original 25 PERI scales that were combined into a measure known as demoralization, based on Jerome Frank's concept which included anxiety, depression, feelings of helplessness, feelings of hopelessness and poor self-esteem ${ }^{20}$. The PERI-D consists of 27-items rated on a 5-point scale. Based on the input from the Honduran team evaluating the interview schedule several modifications were made. Two of the items from the PERI-D were excluded: "When you get angry, how often do you feel uncomfortable, like getting headaches, stomach pains, cold sweats and things like that?" and "In general, if you had to compare yourself with the average (man/woman) your age, what grade would you give yourself during the past year?" It was felt the meaning of those two items would be difficult for Hondurans to interpret. Since the objective of the study was to determine current psychiatric and psychological problems the PERI-D was modified to inquire about the last 7 days rather than the past month. 
DSM-IV diagnosis of PTSD was obtained by using the Composite International Diagnostic Interview (CIDI), Spanish version 2.1, PTSD module ${ }^{21}$. The module used obtained current diagnosis, with each question modified so that it only referred to the hurricane and to no other traumatic event. Presence of current PTSD symptoms and their severity in the past 7 days was further evaluated by using the Impact of Event Scale (IES) ${ }^{22}$. The IES is a brief 15-item self-report screening instrument used to assess symptoms of avoidance and intrusion. Again the items were linked directly to the hurricane rather than being left open to other traumatic events. This was followed by questions evaluating the degree of traumatic exposure that occurred during the hurricane with both open and closedended questions. A single item was included in the interview schedule to attempt to control for the presence of pre-morbid psychological problems "Did you have problems with your nerves before the hurricane?"

To evaluate for the presence of current major depression, a DSM-IV/ICD-10 symptom checklist inquiring into the presence of diagnostic symptoms in the past two weeks was used. This instrument has been used previously in a multi-center study of primary care practices throughout Latin America ${ }^{23}$. The DSM-IV major depression checklist was compared to the CIDI 1.0 module in a primary care clinic setting in Chile. The symptom checklist was found to have a sensitivity of $97 \%$ and specificity of $54 \%{ }^{24}$.

The five-item screen for alcohol misuse, which is part of the Spanish version of the Symptom Reporting Questionnaire (SRQ) was used. The items were modified to tap into behaviors that occurred since the hurricane ${ }^{25}$.

An abbreviated interview was administered to those respondents interviewed twomonths after the disaster two-years later. The
CIDI PTSD module and the MDD checklist were re-administered. Demographic data and what occurred to the individual and family post-disaster were also explored.

The study underwent ethical approval by the institutional review board of Butler Hospital, Providence, RI. The interview schedule was evaluated by the Secretary of Health's office of Honduras and the Pan American Health Organization Honduras office for ethical issues. The study was conducted under the auspices of the Pan American Health Organization/WHO and the Department of Health of Honduras. PAHO/WHO funded the study. Each interviewer was provided a letter of introduction from the Secretary of Health of Honduras identifying them as an interviewer for this study. Written informed consent was obtained both from the person providing the information about the residents of the home and the subject undergoing the more extensive adult interview both at baseline and two-years later.

\section{Data Analysis}

Demoralization based on the PERI-D was examined as both a risk factor for PTSD baseline data, two-months post-disaster using logistic regression, controlled for potential confounders. In addition, a multivariate regression analysis was conducted to examine the extent to which PTSD and other covariates contributed to demoralization. PTSD at two-years post-disaster and its three potential outcomes, remission, new-onset after twomonths, or chronicity were examined using logistic regression to determine if baseline demoralization had a significant role. The potential confounders included in the multivariate and the logistic regression analyses included: gender, age divided into three groups (15-24, 25-59, 60+), marital status, educatio- 
nal attainment (no education, primary, secondary, university), socioeconomic status (low, middle or high based on neighborhood), exposure (high versus low based on selected neighborhoods), exposure index, IES-avoidance subscale, IES-intrusion subscale, and alcohol misuse. MDD obtained at two-months was used in baseline analyses, and MDD obtained at two-years was used for the longitudinal analysis. Backwards regression analyses were utilized to determine the best-fitting models; variables with a $\mathrm{P}<0.1$ were retained in the models. Statistical tests were considered to be significant at the $\mathrm{P}<0.05$ level. The statistical analysis was conducted using the SUDAAN software program to adjust the standard errors (SE) for the stratified sample design and the probability of selection.

\section{Results}

\section{Risk Factors for Demoralization Two-Months After Disaster}

The mean and percentages of the variables used in the analysis are presented in Table 1. Nearly all $(\mathrm{N}=772)$ respondents completed the PERI-D. PERI-D was measured twomonths after the hurricane. A multivariate regression model examining the best fitting model for demoralization shortly after the hurricane found that PTSD, MDD, IES both avoidance and intrusion, having "nerves prior to the hurricane", female gender, being divorced, alcohol misuse and the exposure index all were related to increased demoralization. Socio-economic status, being in a high or low exposed neighborhood, and educational attainment were not associated with demoralization shortly after the disaster (see Table 2). When the sample, was limited to those who participated in the follow up only IES-avoidance was no longer significant.

\section{Role of Demoralization in PTSD Outcome Two-Years After Disaster}

Of the 604 respondents two-years after the hurricane 589 completed the PERI-D. As noted in Table 1, there was no selection bias between participants at two-months and twoyears post-hurricane. PERI-D in a bivariate logistic regression model with PTSD at time 2 was statistically significant $[\mathrm{OR}=4.94$, 95\% CI $(3.37,7.24)]$. The relationship between PTSD at time 2 with demoralization $[\mathrm{OR}=1.81,95 \%(1.11,2.94)]$ remained significant when controlled for potential confounders (MDD at time 2, gender, exposure index, IES-avoidance subscale, SES). In addition increased demoralization at baseline was associated positively with the development of new onset cases [OR $=4.33,95 \% \mathrm{CI}$ $(2.64,7.12)]$ and PTSD chronicity $[\mathrm{OR}=2.53$, $95 \%$ CI $(1.11,5.77)]$; while lower demoralization $[\mathrm{OR}=0.33,95 \% \mathrm{CI}(0.14,0.78)]$ was related to PTSD recovery from baseline. Table 3 provides a summary of these findings. When controlled for potential confounders (MDD at time 2, SES, marital status, age and IESavoidance subscale at time 1) demoralization was no longer associated with new onset PTSD $[O R=1.65,95 \%$ CI $(0.93,2.95)]$. Lower demoralization remained a significant predictor of PTSD recovery $[\mathrm{OR}=0.3295 \%$ CI $(0.14,0.70)]$ even after controlling for potential confounders (MDD at time 2, alcohol misuse). Additionally, higher demoralization remained associated with PTSD chronicity controlled for confounders in a model that appeared unstable (education, gender, marital status, alcohol misuse, exposure index, prior nerves, and MDD at time 1) $[\mathrm{OR}=417.95$, 95\% CI $(8.43,20731.31)]$. 
Table 1

Socio-Demographic and Confounding Variables Obtained at Baseline at Two-Months Post-Disaster

Two-Months

Two-Years

\begin{tabular}{|c|c|c|c|c|}
\hline Variable & Mean & SE & Mean & SE \\
\hline PERI-D & 1.2 & 0.02 & 1.2 & 0.03 \\
\hline IES-Avoidance & 16.4 & 0.34 & 16.4 & 0.41 \\
\hline IES-Intrusion & 12.4 & 0.33 & 12.46 & 0.38 \\
\hline Alcohol Misuse & 0.12 & 0.02 & 0.12 & 0.03 \\
\hline \multirow[t]{2}{*}{ Exposure Index } & 0.76 & 0.03 & 0.74 & 0.04 \\
\hline & $\%$ & $\mathrm{SE}$ & $\%$ & $\mathrm{SE}$ \\
\hline Female & 61.4 & 1.75 & 62.0 & 2.01 \\
\hline \multicolumn{5}{|l|}{ Age Group } \\
\hline $15-24$ & 31.2 & 1.69 & 31.2 & 1.95 \\
\hline $25-59$ & 56.4 & 1.78 & 56.7 & 2.05 \\
\hline $60+$ & 12.5 & 1.17 & 12.1 & 1.31 \\
\hline \multicolumn{5}{|l|}{ Marital Status } \\
\hline Single & 38.0 & 1.77 & 37.1 & 2.2 \\
\hline Married & 51.6 & 1.80 & 52.1 & 2.07 \\
\hline Divorced & 6.4 & 0.90 & 6.6 & 1.05 \\
\hline Widowed & 4.0 & 0.65 & 4.2 & 0.77 \\
\hline \multicolumn{5}{|l|}{ Education } \\
\hline No School & 6.7 & 0.87 & 6.4 & 0.98 \\
\hline Primary & 36.1 & 1.57 & 34.5 & 1.82 \\
\hline Secondary & 34.9 & 1.72 & 37.4 & 2.01 \\
\hline University & 22.3 & 1.33 & 21.7 & 1.57 \\
\hline \multicolumn{5}{|l|}{ SES } \\
\hline High & 25.0 & 0.68 & 22.3 & 1.2 \\
\hline Middle & 25.1 & 0.64 & 25.8 & 1.1 \\
\hline Low & 49.9 & 0.77 & 52.0 & 1.3 \\
\hline High Exposure & 50.0 & 0.77 & 48.1 & 1.28 \\
\hline Prior Nerves & 20.1 & 1.43 & 20.2 & 1.63 \\
\hline MDD & 19.5 & 1.43 & 19.4 & 1.64 \\
\hline PTSD & 10.6 & 1.11 & 11.8 & 1.32 \\
\hline MDD (two-years) & & & 22.3 & 1.67 \\
\hline PTSD (two-years) & & & 20.5 & 1.66 \\
\hline
\end{tabular}




\section{ROBERT KOHN}

Table 2

PERI-D Best Fitting Multivariate Regression Analysis Two-Months after the Hurricane (N - 754)

Time 1 Sample

Time 2 Sample

\begin{tabular}{|c|c|c|c|c|c|}
\hline \multicolumn{2}{|l|}{ R Square } & \multicolumn{3}{|c|}{0.53} & 0.54 \\
\hline Independent Variables & DF & Wald $\mathrm{F}$ & P-value & Wald $\mathrm{F}$ & P-Value \\
\hline Overall Model & 12 & 488.89 & 0.00001 & 429.96 & 0.00001 \\
\hline Model Minus Intercept & 11 & 44.70 & 0.00001 & 50.32 & 0.00001 \\
\hline \multicolumn{6}{|l|}{ Intercept } \\
\hline PTSD & 1 & 7.96 & 0.0049 & 4.35 & 0.0373 \\
\hline Sex & 1 & 11.46 & 0.0007 & 18.46 & 0.00001 \\
\hline Marital Status & 3 & 3.01 & 0.0296 & 3.07 & 0.0272 \\
\hline IES - Intrusion & 1 & 26.91 & 0.00001 & 30.06 & 0.00001 \\
\hline IES - Avoidance & 1 & 4.45 & 0.0352 & 1.43 & 0.2315 \\
\hline Alcohol Misuse & 1 & 5.17 & 0.0233 & 40.54 & 0.00001 \\
\hline Exposure Index & 1 & 21.15 & 0.00001 & 13.58 & 0.0002 \\
\hline MDD & 1 & 96.92 & 0.00001 & 67.00 & 0.00001 \\
\hline Prior Nerves & 1 & 18.19 & 0.00001 & 14.81 & 0.00001 \\
\hline
\end{tabular}

Table 3

PERI-D and PTSD Outcomes Odds Ratio with 95\%CI, Mean and Standard Error without controlling for confounders

\begin{tabular}{|c|c|c|c|c|c|c|c|c|}
\hline PTSD & OR & $95 \% \mathrm{CI}$ & $\mathrm{N}$ & Mean & SE & $\mathrm{N}$ & Mean & SE \\
\hline \multicolumn{9}{|c|}{ Baseline Population } \\
\hline & & & T1 NO & & & T1 YES & & \\
\hline Two-Months & 10.45 & $6.36,17.17$ & 671 & 1.09 & 0.02 & 83 & 1.97 & 0.07 \\
\hline \multicolumn{9}{|c|}{ Follow-up Population } \\
\hline & & & T1 NO & & & T1 YES & & \\
\hline \multirow[t]{2}{*}{ Two-Months } & 9.29 & $5.49,15.73$ & 504 & 1.10 & 0.02 & 71 & 1.94 & 0.08 \\
\hline & & & $\mathrm{T} 2 \mathrm{NO}$ & & & T2 YES & & \\
\hline \multirow[t]{2}{*}{ Two-Years } & 4.94 & $3.37,7.24$ & 462 & 1.09 & 0.02 & 113 & 1.71 & 0.07 \\
\hline & & & T1 YES & & & T2 YES & & \\
\hline \multirow[t]{2}{*}{ Chronic } & 2.53 & $1.11,5.77$ & 50 & 1.82 & 0.07 & 33 & 2.18 & 0.12 \\
\hline & & & T1 NO & & & T2 YES & & \\
\hline \multirow[t]{2}{*}{ New Onset } & 4.33 & $2.64,7.12$ & 420 & 1.04 & 0.02 & 74 & 1.47 & 0.07 \\
\hline & & & T1 YES & & & $\mathrm{T} 2 \mathrm{NO}$ & & \\
\hline Remission & 0.33 & $0.14,0.78$ & 33 & 2.18 & 0.12 & 34 & 1.73 & 0.09 \\
\hline
\end{tabular}




\section{Discussion}

Demoralization is a risk factor for developing PTSD acutely after a natural disaster. Demoralization was independent of major depressive symptoms, alcohol misuse, and having complaints of "prior nerves". Demoralization remained a significant risk factor after controlling for exposure, severity of PTSD, and socio-demographic variables. Demoralization also was predictive of having PTSD two-years after the natural disaster. Lower demoralization at baseline was a predictive factor in PTSD recovery, while higher demoralization was predictive of PTSD chronicity. Interestingly, demoralization once controlled for other covariates was no longer predictive of new onset of PTSD between two-months and two-years post-disaster.

This study has a number of limitations. Ideally, it would have been preferable to measure demoralization, PERI-D, longitudinally as well. The only diagnosis obtained using a structured diagnostic instrument was PTSD. The diagnosis of MDD used a checklist and therefore lacked the impairment criteria. A proxy "problems with nerves" was used to obtain a diagnosis of past-disorders. The results also are not generalizable to Honduras as a nation or Tegucigalpa the capital city as those with higher SES were oversampled in order to provide data relevant to all segments of the population. Despite this, in this analysis SES had only a minimal role.

Demoralization shortly following a disaster appears to be a good predictor of prognosis. Those with elevated levels of demoralization do poorly with risk for PTSD and those with lower levels appear to have considerably better outcomes. This finding would suggest that a brief simple questionnaire that measures demoralization might be a useful screening tool clinically in identify- ing individuals who may be at increased risk for PTSD in the short-term, as well as in the long-term following a disaster. This type of screening instrument can easily be implemented at the primary care level to identify persons who might require more intense intervention. Future research on the longitudinal outcome of disasters should consider implementing a measure of demoralization to further elucidate its predictive utility in the outcome of PTSD, as well as other post-disaster psychopathology.

\section{Acknowledgements}

The author wishes to thank the Pan American Health Organization/World Health Organization who provided the funding for the baseline study and helped coordinate the longitudinal study with the Ministry of Health of Honduras. We also wish to thank the individuals who agreed to participate in the study and our interviews. In addition, I wish to thank Itzhak Levav, MD who helped design the study.

\section{References}

1. de Figueiredo JM. Depression and demoralization: phenomenologic differences and research perspectives. Compr Psychiatry 1993; 34: 308-311.

2. Cockram CA, Doros G, de Figueiredo JM. Diagnosis and measurement of subjective incompetence: the clinical hallmark of demoralization. Psychother Psychosom 2009; 78: 342-345.

3. Sansone RA, Sansone LA. Demoralization in patients with medical illness. Psychiatry (Edgmont) 2010; 7: 42-45.

4. Erikson KT. Disaster at Buffalo Creek. Loss of communality at Buffalo Creek. Am J Psychiatry 1976; 133: 302-305.

5. Goldberg DP, Gater R, Sartorius N, Ustun TB, Piccinelli M, Gureje O, et al. The validity of two versions of the 
GHQ in the WHO study of mental illness in general health care. Psychol Med 1997; 27: 191-197.

6. Buesenberg M, Orley J. A User's Guide to the Self Reporting Questionnaire (SRQ). Geneva: World Mental Health Organization; 1994.

7. Kohn R, Levav I, Donaire Garcia I, Machuca M, Tamashiro R. Prevalence, risk factors, and aging vulnerability for psychopathology following a natural disaster in a developing country. Int J Geriatr Psychiatry 2005; 20: 835-841.

8. Kohn R, Levav I, Donaire I, Machuca M, Tamashiro R. Psychological and psychopathological reactions in Honduras following Hurricane Mitch: implications for service planning. Rev Panam Salud Publica 2005; 18: 287-295.

9. Líndal E, Stefánsson JG. The long-term psychological effect of fatal accidents at sea on survivors: a cross-sectional study of North-Atlantic seamen. Soc Psychiatry Psychiatr Epidemiol 2011; 46: 239-246.

10. Onder E, Tural U, Aker T, Kiliç C, Erdoğan S. Prevalence of psychiatric disorders three years after the 1999 earthquake in Turkey: Marmara Earthquake Survey (MES). Soc Psychiatry Psychiatr Epidemiol 2006; 41: 868-874.

11. Neria Y, Nandi A, Galea S. Post-traumatic stress disorder following disasters: a systematic review. Psychol Med 2008; 38: 467-480.

12. Goenjian AK, Molina L, Steinberg AM, Fairbanks LA, Alvarez ML, Goenjian HA, et al. Posttraumatic stress and depressive reactions among Nicaraguan adolescents after Hurricane Mitch. Am J Psychiatry 2001; 158: 788-794.

13. Wang X, Gao L, Shinfuku N, Zhang H, Zhao C, Shen Y. Longitudinal study of earthquake-related PTSD in a randomly selected community sample in north China. Am J Psychiatry 2000; 157: 1260-1266.

14. Holgersen KH, Klöckner CA, Boe HJ, Weisaeth L, Holen A. Disaster survivors in their third decade: trajectories of initial stress responses and long-term course of mental health. J Trauma Stress 2011; 24: 334-341.

15. Dohrenwend BP, Shrout PE, Egri G, Mendelsohn FS. Measures of nonspecific psychological distress and other dimensions of psychopathology in the general population. Arch Gen Psychiatry 1980; 37: 1229-1236.
16. Kissane DW, Wein S, Love A, Lee XQ, Kee PL, Clarke DM. The Demoralization Scale: a report of its development and preliminary validation. J Palliat Care 2004; 20: 269-276.

17. Rogers R, Sewell KW, Harrison KS, Jordan MJ. The MMPI-2 Restructured Clinical Scales: a paradigmatic shift in scale development. J Pers Assess 2006; 87: 139-147.

18. Pan American Health Organization. Impact of Hurricane Mitch on Central America. Epidemiol Bull 1998; 19(4): $1-13$.

19. Kish L. Survey Sampling. New York: John Wiley \& Sons; 1965.

20. Frank JD. Persuasion and Healing. Baltimore: John Hopkins University Press; 1973.

21. World Health Organization. Composite International Diagnostic Interview, version 2.1. Geneva: WHO; 1997.

22. Horwitz M, Wilner N, Alvarez W. Impact of Event Scale: a measure of subjective stress. Psychosom Med 1979; 41: 209-218.

23. Levav I, Kohn R, Montoya I, Palacio C, Rozic P, Salano I, et al. Training Latin American primary care physicians in the WPA module on depression: results of a multicenter trial. Psychol Med 2005; 35: 35-45.

24. Vicente B, Kohn R, Levav I, Espejo F, Saldivia S, Sartorius N. Training primary care physicians in Chile in the diagnosis and treatment of depression. J Affect Disord 2007; 98: 121-127.

25. Climent CE, Arango MV. Manual de psiquiatría para trabajadores de atención primaria. Series Paltex Para Técnicos Médicos y Auxilares. Washington, DC: Pan American Health Organization; 1983.

Corresponding author:

Robert Kohn, MD

The Miriam Hospital, 164 Summit Avenue

Providence, RI, USA 02906

Telephone: 1-401-793-4300

Fax: 1-401-793-4312

E-mail: Robert_Kohn@brown.edu 